\title{
Study on Overseas Chinese Education under Perspective of Postmodernism Curriculum Theory
}

\author{
Fangfang Huang ${ }^{1}$ \\ ${ }^{1}$ Jinan University, School of Chinese, Guangzhou, 510610 \\ hunter2011@foxmail.com
}

Keywords: Curriculum View; Postmodernism; Overseas Chinese Education

\begin{abstract}
The postmodern curriculum with Dole as the representative person advocates anti-center, anti-authority, advocates an open, collaborative teaching, focuses on learning differences, diversity and so on, these ideas offer a new method to solve the current teacher-student relationship on overseas Chinese education, teaching problems prepared and reform pedagogy and provide a new idea: build a platform for dialogue equality, teacher-student interaction and cooperation advocacy, change the traditional role of teachers; select open textbook design, rich content of textbooks, rich modernization means for teaching materials; focus on generative teaching goals, build interactive teaching implementation and use diversified teaching evaluation.
\end{abstract}

\section{Introduction}

In recent years, with the improvement of China's international status, overseas Chinese education is been taken more and more attention around the world, demand for Chinese language study showed a rapid growth trend. But in a time of rapid development, but also encountered many problems and difficulties, in different forms, in different degrees, restrict its further development. Chinese school teachers as knowledge is narrow, outdated teaching methods, ideas, and the concept of education more conservative [1]. Select from content to specific materials prepared by the low degree of localization [2]. The traditional teaching model can not adapt to overseas Chinese education, teachers in the classroom most stern, exchanges between teachers and students is more serious, generally said the teacher, the students in mind, or the teacher asked students to answer [3]. Thus, teachers, teaching materials and other issues is a common problem faced by countries in Chinese language education, it has become a constraining the development of overseas Chinese education three stumbling block. And with Dole as the representative of postmodern curriculum was to solve the current problems of Overseas Chinese Education provides a new way of thinking.

Postmodernism is produced around the 1960s in Western countries pan-cultural trends at the moment. Later, the education sessions theoretical research ideas into their curriculum. Although postmodern theory education at home and abroad is heated discussion, but in theory and practical courses it is rarely mentioned in Chinese Education. This paper will combine the three outstanding issues on the basis of Chinese Education in the post-modernist reference to the Overseas Chinese Education Curriculum Theory expand research, come up with a new idea of development of overseas Chinese education, the development of overseas Chinese education under the new situation there Targeted

\section{Postmodern Curriculum Analysis}

The Proposition of Postmodern Curriculum. Postmodernism is produced since the 1960s in Western countries, modernism and modernity to question the rationality and subversion of pan-cultural trends. It is a revision and reconstruction of modernism, advocating anti-center, anti-authority, promote irrational, uncertainty, equality, focusing on differences, against the same, to promote diversification of education [4]. Postmodernism Curriculum Theory arises after the emergence and development of modernism as the foundation of cultural trends.

The Difference Between Post-Modern Curriculum Perspective and Modern Curriculum. Postmodern curriculum is for the modern curriculum concept put forward. Postmodernism is the 
critique and reconstruction of principles for curriculum model with Taylor's theory of modernism. To further understanding of the post-modern curriculum, now the difference between the list after modern curriculum and modern courses are as follows:

\begin{tabular}{|l|l|l|}
\hline & Modern Curriculum & Postmodern curriculum \\
\hline Course Objectives & Preset in advance & Dynamically generated \\
\hline Course content & Objectivity, neutrality & Pluralism \\
\hline Course Objectives & To grasp the knowledge-based & Develop competency \\
\hline $\begin{array}{l}\text { Curriculum } \\
\text { Implementation }\end{array}$ & Other organization, the program type & Develop competency \\
\hline $\begin{array}{l}\text { Course Evaluation } \\
\text { Teacher-student } \\
\text { relationship }\end{array}$ & Quantify, results & $\begin{array}{l}\text { Qualitative, } \\
\text { process-oriented }\end{array}$ \\
\hline
\end{tabular}

The Basic Idea of Postmodern Curriculum. View of traditional courses focus on specific curriculum objectives and clear, but the classroom is complex, this closed book well in advance, with a resistance to change, rejection of interference and other limitations curriculum goals difficult to adapt to the needs of teaching. And in the sight of the postmodern curriculum as a kind of cultural development and creative process, teachers and students to participate in the exploration activities in meaning, spirit, experience, ability to build process. They believe the course should not be entirely predetermined objective, but should be rich, uncertain, by teachers and students in the teaching process together through interaction and mutual consultations dynamically generated, along with teachers and students in the teaching situation, changes under teaching conditions and constantly adjust dynamically generated. In short, the goal is to create a course in the curriculum process and transformed from.

Modern theory of knowledge that knowledge is external, determine creed. This view is reflected in the curriculum, course content is determined, objective and neutral knowledge, teaching those controversial content, the need to explore are keen to avoid. In the post-modernist view, the world is diverse, uncertain, can it be understood from different angles. This view is reflected in the curriculum is that students no longer as passive recipients of knowledge, obey the instructions of teachers, and to take their interests, needs and perspectives of direct dialogue with the objective world. Course content is absolutely objective and stability not only of knowledge, but should have the richness, diversity of content, which includes curriculum materials constituting the multicultural content, methods constitute the course content, skills, emotions, attitudes, values and so diversified, the students teaching materials interpretation diversification.

The pursuit of traditional teaching process procedures, customary for students to teachers along the orbit designed to passively accept the final has set a good answer. After the implementation of modern curriculum is no longer focused on indoctrination and interpretation, but the curriculum implementation regarded as an open system, teachers are participants in curriculum implementation organizer, guide and equal dialogue on an equal footing of students and teachers around common the topic, the process to work together to build courses through dialogue and cooperation, and this process is not the role of teachers direct students to more from teachers and students, life, dialogue between students of the exchange process. That course is no longer the runway, and to become self-running process, curriculum implementation from the teachings of the steering autonomous, dialogue, inquiry.

In the framework of modern curriculum evaluation, the evaluation aims to identify, method of evaluation is to find lack of evaluation methods are mostly based on the examination as a yardstick to evaluate the subject of evaluation is more a single teacher [5]. Then modern curriculum scholars believe, curriculum evaluation under the auspices of a single modernity, closed, uniform evaluation criteria ignored the development of the educated emotion, will, motivation, interest and so on. In the framework of post-modernism, " should be evaluated as a feedback, as do - criticism - do Criticism part of this cycle of focus now is to establish a community designed to help individuals through intellectual and social development of the individual capacity of criticism and dialogue [4]. 
in the post-modern curriculum, teachers and an external evaluator to evaluate shared responsibility. Value pluralism, respect for differences, the development of the evaluation function is Postmodernism course the main characteristics of the evaluation.

In the modern view of curriculum, teachers are in a position of authority, is imparting knowledge, students are passive recipients of knowledge. Then the Postmodern Curriculum think teachers just "among equals", "is within that scenario leader, rather than external dictator", the student is no longer a teacher understanding and transformation of the object, but has a unique cultural experience, needs, emotions, body fresh personality. Reflective relationship is an equal exchanges and dialogue between teachers and students. Authority by the concerns of teachers and full internal critical dialogue develop, teachers and students grow together in interactive activities. The relationship between teachers is changing from one-way teaching turns to the students and teachers, the dialogue between students and students.

\section{The Enlightenment of Postmodernism Curriculum on Chinese Education}

The Position of Teacher under Postmodernism Perspective of Overseas Chinese Education. Chinese teachers should realize that every student has an independent personality and a rich inner world, we need to understand and respect, and therefore in the process of imparting knowledge, should strive to create a conducive atmosphere for teaching communication and inquiry, respect for the views of students and Opinions, to encourage students to divergent innovation, enable students to truly become the main body of learning, actively involved in the teaching process. As explained "Kua Fu's race with the sun", the point is we know Kua Fu's race with the sun reflects the ancient people to explore the natural, strong desire to conquer nature and indomitable will. However, in actual explanation, many students can not understand this behavior Kua Fu's race with the sun represent meaning. They think that it is ridiculous braggadocio, is presumptuous. At this time, if the teacher requires students to accept it instilled views, students are not allowed to mention too many questions or diverging themes, it will greatly against student interest in learning the Chinese language, Chinese teachers should therefore dialogue on the basis of equality, freedom elaborate encourage everyone, then from the man on the moon dream come true to guide students to understand the inherent Kua Fu's race with the sun people have grand ambitions or great strength and courage of the metaphorical meaning.

Due to differences in living conditions and cultural background, Chinese students have their own unique individual experience, coupled with unique Chinese language ambiguity and metaphorical characteristics, such as individual knowledge and understanding of learning adds uncertainty, resulting in a explore diversity issues conclusions, which provides a prerequisite for the interaction and cooperation of teachers and students. Therefore, in teaching students and teachers can explore freely around a theme carried out between teachers and students, were colliding with each other in response to real spiritual and views between students and students, making sense of the world fusion occurs between the two sides. As Chinese culture about goodness of human nature interpretation there, evil theory, theory and other benefits or reduce evil harm. With different religious and cultural backgrounds in the Chinese students it is not the person appears to humanity itself, but God conferred their behavior bound by doctrine. For such a fundamental philosophical questions, the discussion is the best way. Students can express their views, explore the different cultures of human should be how like? How to regulate their own behavior? Teaching is no longer a process whereby the implementation of lesson plans, and to become teachers and to develop courses, rich curriculum process, teachers and students full of personalized creative process.

One-way relationship between teachers' teaching is changing from the teacher turned to the dialogue and cooperation between teachers and students, the role of Chinese teachers have a major change accordingly. First Chinese teachers should shift from executive lesson plans for curriculum and teaching builders. Chinese teacher to the student's background, interests, needs and abilities, select the appropriate difficulty level close to the student life of teaching content and objectives, and to optimize the combination of the actual situation, teaching materials, and construct scenarios for the actual teaching curriculum. Second, Chinese teachers should shift from knowledge to students 
who pass the guide. Chinese students in the learning process, will inevitably encounter to be a culture of learning and their own cultural conflict, confusion and even chaos, when teachers do not force students must be recognized and accepted, and to examine with an open mind culture The difference, and guide students to promote the comparison of old and new knowledge, blend in thinking contradictions thus construct new cognitive structures.

Textbooks Choreography. Postmodernism Curriculum Theory suitable for the preparation of Chinese teaching Chinese students need to provide ideas, that textbook design must reflect the richness and flexible, want to provide students with an open space initiative thinking process of teachers for teaching self-creation, Students independent study leave necessary space. For example, we read textbooks now used in most part to help reading system including anthology, texts, exercises system three systems, requires students to text a "global perception", "read", and through the grasp of the language in the form of text and then experience the author emotional, cognitive text content. All the contents of textbooks are arranged around the reading ability of the teaching mode makes reading into a mechanical training cycle, students as human nature was "instrumental" to oblivion. But Correspondingly, Postmodernism view is give us some inspiration, as can design a series of text to guide students to analyze critical issues, develop their critical thinking and improve their analytical, critical ability; after school Exercise can continue to guide the students to contact their own life experience, to analyze, critically to treat the text, and allow students based on their own interest to read some books related to the content of the text.

Overseas Chinese Education has its own characteristics, so can not directly use Chinese as a Foreign Language teaching materials, and should be based on the actual situation of Chinese students, the preparation of materials suited to their needs. Postmodern curriculum makes us realize the diversification characteristic of knowledge, and therefore should be designed to take Chinese language teaching multicultural perspectives, cultures and knowledge can make contact with the students, understanding, respect and appreciation, as in the preparation of materials to close attention and study psychology and Chinese adolescents countries actually Chinese education, learning characteristics, teaching content to content-based Chinese culture, but also take into account overseas students' cultural practices, such as addition to selecting local and surrounding area economy, tourism, foreign affairs and other topics, but also more compiled some overseas Chinese in overseas story of struggle and local customs, and domestic and comparison. These allow students to produce intimacy, in order to mobilize their enthusiasm to learn Chinese.

Overseas Chinese mother tongue education due to lack of contextualized learning environment, how the rich and diverse cultural content into the scene show the Chinese language teaching students to become a major problem. The combination of Chinese teaching with modern educational technology is aims to provide a solution. In teaching materials choreography, it must be combined with modern educational methods and ideas, full networking, multimedia and other teaching tools provide an interesting and real situation for learning, so that they can feel, feel the Chinese culture behind the language. As Ma Zhiyuan "Tian Jing Sha • Autumn Thoughts" "Ku Teng trees faint crow, bridges people, Road westerly skinny horse, heartbroken people in the End of the World", although one of the words will be interpreted individually, but for Chinese students let their feelings or experience implied a certain degree of difficulty, but if do combine relevant text, picture and video images, etc., can stimulate different senses of learners, mobilize learners emotional involvement, thereby improving Chinese the effect of education.

Teaching Reform. For a long time teaching implementing the Overseas Chinese Education has been one-sided emphasis of teaching objectives and content of the presets, certainty, but the main development and diversification of Chinese students, the differences in the formation of a sharp contradiction. Ancient Chinese courses such as difficult, boring content, students have little interest in this, and therefore must be set in Ancient Chinese Teaching open, generative, creative development teaching goals that we should learn the language of the student sensitivity, interest measure, the difficulty, the difference of materials for flexible learning schedule adjustments reflect flexibility and regional. As explained "The Analects", since a lot of knowledge and cultural point of "The Analects" involved student backgrounds and interests are not the same, before the class is 
difficult to determine a unified educational goals, so we can start to play in the classroom film "Confucius", after discussion with the students, to understand students' point of interest, and to determine the teaching objectives. If students want to know some of them famous, such as "different phase plan is not", "Do unto others, do not impose on others" and so on; some seventy-two disciples of Confucius, especially Yanhui, Zi, Ran Qiu impressed. This time it can combine student interest, adjustments and build a different formula teaching.

Teaching implemented in the post-modern view of curriculum teaching is no longer a first course or plan what you want to take a modified procedure, but a real creative process, the dialogue process. As in the teaching, we should change the traditional "band doubt read the text" teaching methods, to "read the text of doubt," the dialogue, inquiry. For "King outside the King" literary works there is "blank", such as "image out of images" of poetry, prose, plays enrich the "subtext" and the novel "suspense" and so can stimulate the imagination of students force, instead of dialogue, due to differences in Chinese students' background knowledge, knowledge structure, aesthetic ability may appear vastly different answers, but that is the multiple interpretation of the text and re-creation.

Respected pluralism, diversity is an important value orientation of post-modernism, reflecting the performance of a diversified curriculum evaluation on curriculum evaluation. This diversity Specific performance: a diversity of subject in curriculum evaluation, namely teachers, learners, schools, families and communities need to be evaluated Chinese from their own perspective. Two review content diversification, that Chinese students should not be evaluated merely grasp how much Chinese vocabulary, how many Chinese can read articles, and more Chinese students through learning can really internalized into their own possession, Chinese education students feelings, attitudes and values. Diversification three evaluation methods, upcoming diagnostic evaluation, developmental evaluation and summative combination, and pay special attention to the development of evaluation; evaluation of the amount and quality of the evaluation of the combination, and to pay attention to the quality of the evaluation. Such as teachers not only need the amount of evaluation at the time of the evaluation of student achievement, such as test scores, and more importantly, the quality of the evaluation, such as group presentations on the activity classes, extended class under knowledge and so on.

Postmodern curriculum theory provides a new perspective for program development, but also provides a new idea and a new enlightenment for addressing our current outstanding problems in Chinese education. But the idealism component and the lack of interoperability on modern curriculum theory also make the concrete implementation difficulties. How to take flexible use of post-modern curriculum and how to make it can to serve our future Chinese education is a big problem.

\section{Acknowledgements}

Project: Universities Fundamental Research Funds of Central Government (13JNQN029), Jinan University, School of Chinese "Campus Research Program Fund "; Degrees and Graduate Education Reform Project fund of Jinan University (14ZD09).

\section{References}

[1] Z. Chen. The Development Trend of Chinese Education in Southeast Asia, Problems and Countermeasures. Yunnan Normal University. (Foreign Language Teaching and Research Edition) 2007 (4): 26-30.

[2] X.X. Gao, C. Cheng. Italy Overview of Chinese Education Chinese Youth. Science Educ, 2011 (2): 83-85.

[3] S.J. Ou. The Chinese Education Problems in Australia and New Zealand. Guangxi Radio and TV University, 2012 (3): 69-72. 
[4] William E. Dole. Postmodern Curriculum. Translated by Wang Hongyu. Beijing: Education Science Press, 2001.

[5] X.Z. Wang, Z.M. Guo. The Development in "Difference"-Postmodernism and Modernism Curriculum View of The "People" Change. Hebei Normal University (Education Science Edition), 2009 (11): 128-132. 